\title{
Temperature Effect on the Selective Hydration of Sodium Ion in Nitrobenzene
}

\author{
Toshiyuki OsakaI, ${ }^{* \dagger}$ Akiko ToKura,* Hajime Ogawa,* Hiroki Hotta,* Masaru Kawakami,** \\ and Kazuyuki AKASAKA***
}

*Department of Chemistry, Faculty of Science, Kobe University, Nada, Kobe 657-8501, Japan

**Department of Molecular Science, Graduate School of Science and Technology,

Kobe University, Nada, Kobe 657-8501, Japan

***Department of Biotechnological Science, School of Biology-Oriented Science and Technology,

Kinki University, Uchita-cho, Wakayama 649-6493, Japan

\begin{abstract}
The effect of the temperature on the co-extraction of water molecules with $\mathrm{Na}^{+}$from water to nitrobenzene (NB) in the presence of dipicrylaminate ion has been studied. The number $(n)$ of water molecules co-extracted with a $\mathrm{Na}^{+}$ion, as measured by the Karl Fischer method, increased from 3.1 to 5.2 with increasing temperature $\left(6-65^{\circ} \mathrm{C}\right)$. This observation is in apparent contradiction to the expectation from simple thermodynamics because hydration is generally an entropically unfavorable process. Additional ${ }^{1} \mathrm{H}$ NMR experiments for the selective hydration of $\mathrm{Na}^{+}$in deuterated NB have confirmed that the association constants of water with $\mathrm{Na}^{+}$indeed decrease with increasing temperature. On the other hand, however, it has been shown that water solubility into NB substantially increases with temperature. We conclude that the latter effect overwhelms the former unfavorable entropy effect, which results in a net increase of the $n$-value, as observed.
\end{abstract}

(Received July 9, 2003; Accepted August 14, 2003)

\section{Introduction}

For many years much attention has been directed towards the co-extraction of water to water immiscible organic solvents with hydrophilic inorganic ions, ${ }^{1-9}$ including $\mathrm{Li}^{+}, \mathrm{Na}^{+}, \mathrm{Ca}^{2+}$, and $\mathrm{Cl}^{-}$ and also with organic ions ${ }^{9-11}$ having dissociated groups, such as $-\mathrm{CO}_{2}{ }^{-}$and $-\mathrm{NH}_{3}{ }^{+}$. Even water-immiscible organic solvents, such as nitrobenzene (NB), usually dissolve a considerable amount of water (e.g. $168 \mathrm{mM} \mathrm{H} \mathrm{H}_{2} \mathrm{O}$ in $\mathrm{NB}$ at $25^{\circ} \mathrm{C} ;{ }^{8} \mathrm{M}=\mathrm{mol}$ $\left.\mathrm{dm}^{-3}\right)$. Accordingly, the co-extraction of water with ions can be elucidated in terms of the selective hydration of ions in mixed solvents. ${ }^{12}$ This is a key concept intimately related to important ion-transfer processes, not only in separation and detection systems (e.g. solvent extraction, membrane transport, ionselective electrodes), but also in biological systems (lipid membrane, ion channels, etc.). In recent years the co-transport of water by ions has been dealt with by molecular dynamic simulations. ${ }^{13-15}$

In solvent-extraction studies, ${ }^{1-8,10,11}$ the number $(n)$ of water molecules co-extracted with an ion was determined by the Karl Fischer method. However, it has frequently been asked whether the ion is really bound to water molecules in organic solvents. The answer was given by a ${ }^{1} \mathrm{H}$ NMR study ${ }^{16}$ on the selective hydration of anions $\left(\mathrm{X}^{-}=\mathrm{Cl}^{-}, \mathrm{Br}^{-}, \mathrm{I}^{-}, \mathrm{NO}_{3}^{-}, \mathrm{ClO}_{4}^{-}, \mathrm{SCN}^{-}\right)$in deuterated $\mathrm{NB}\left(\mathrm{NB}-\mathrm{d}_{5}\right)$; the chemical shift of water protons changed to lower magnetic fields with the addition of $\mathrm{X}^{-}$, giving evidence for ion-water interactions. It was also found that the

$\dagger$ To whom correspondence should be addressed.

E-mail: osakai@kobe-u.ac.jp selective hydration of anions can be elucidated in terms of a successive reaction mechanism: $\mathrm{X}^{-}\left(\mathrm{H}_{2} \mathrm{O}\right)_{m-1}+\mathrm{H}_{2} \mathrm{O} \rightleftharpoons$ $\mathrm{X}^{-}\left(\mathrm{H}_{2} \mathrm{O}\right)_{m}(m=1,2,3, \cdots)$. Thus, the observed hydration number (i.e. the $n$ value) does not need to be an integer, since it is always given as an averaged value over several species in different hydration states.

The important role of water molecules in the Gibbs energy of transfer of hydrophilic ions between two immiscible liquids was discussed by Osakai and Ebina ${ }^{17,18}$ and Sánchez et al. ${ }^{19}$ based on a model in which a hydrophilic ion transfers across the organic solvent $(\mathrm{O}) /$ water $(\mathrm{W})$ interface as a hydrated ion. The model gave a better account of the transfer energies of hydrophilic ions than the previous models in which the role of the hydrated water molecules was not taken into consideration. Recently, the entropy of ion transfer across the NB/W interface was accurately determined for various ions by means of a W/O/W thermocouple, ${ }^{20}$ which showed the importance of hydrated water molecules in determining the transfer entropy of relatively hydrophilic ions $\left(\mathrm{Na}^{+}, \mathrm{K}^{+}, \mathrm{Br}^{-}\right.$, etc. $)$.

For gaining further insight into the mechanisms of selective hydration of ions, it seems to be important to examine the temperature dependence. However, to the authors' knowledge, there has been only one report by Rais et al., ${ }^{21}$ in which the temperature dependence of the extraction of alkali metal dipicrylaminates into $\mathrm{NB}$ is discussed in terms of the temperature dependence of the water solubility in NB.

In the present study we have focused on $\mathrm{Na}^{+}$and have examined the temperature dependence of the number of cotransported water molecules per $\mathrm{Na}^{+}$ion (i.e. the $n$ value). Previous studies show that the $\mathrm{Na}^{+}$ion co-transports as many as four water molecules at $25^{\circ} \mathrm{C} .{ }^{1,2,8}$ In the present study, we found 
that the $n$ value increases with the temperature. This finding was unexpected in terms of an unfavorable entropy in ion solvation. However, additional ${ }^{1} \mathrm{H}-\mathrm{NMR}$ measurements revealed that the strong increase in water solubility in NB actually overcomes the unfavorable entropy effect, and increases $n$ with the temperature.

\section{Experimental}

\section{Chemicals}

Sodium dipicrylaminate (NaDPA) was purchased from Tokyo Kasei Kogyo Co., Ltd. and dried under reduced pressure for at least $5 \mathrm{~h}$ before use. Analytical-grade NB was treated before use with activated alumina (Wako Pure Chemical Industries, Ltd.; 200 mesh for column chromatography). All other reagents were of analytical grade and used without further purification.

\section{Distribution experiments}

Aqueous solutions of 0 - $20 \mathrm{mM}$ NaDPA, which contained 0.1 $\mathrm{M} \mathrm{NaCl}$ to prevent the formation of microemulsions, were prepared; the $\mathrm{pH}$ was adjusted to 10 with $\mathrm{NaOH}$. A $10 \mathrm{~mL}$ aqueous solution and pure NB of the same volume were put in a glass bottle $(25 \mathrm{~mL})$ with a Teflon cap, shaken in a water bath thermostated at $6,15,25,35,45,55$, or $65^{\circ} \mathrm{C}$ for $3 \mathrm{~h}$, and then separated by allowing to stand for at least a half day. A preliminary experiment showed that these operations achieved the distribution equilibrium. The aqueous phase was pipetted off from the glass bottle directly when placed in a water bath, and an aliquot of the aqueous solution was subjected to a spectrophotometric determination of $\mathrm{DPA}^{-}\left(\varepsilon=2.61 \times 10^{4}\right.$ at $428 \mathrm{~nm}) ; 8$ the aqueous solution was appropriately diluted in advance to prevent the solution from becoming turbid, probably due to microemulsion formation. Then, an aliquot $(0.5 \mathrm{~mL})$ of the NB phase in the bottle was slowly drawn off using a microsyringe and subjected to a determination of the water concentration by means of a Karl Fischer coulometer (Kishida Chemicals CA-20).

\section{${ }^{1} \mathrm{H}$ NMR measurements}

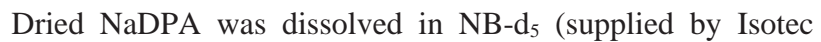
Inc.; $99.5 \%$ atom D) at different concentrations $(0-20 \mathrm{mM})$; the solvent was dried in advance with a molecular sieve (4A; Wako). Using these solutions, sample solutions containing more than 10 different water concentrations were prepared, as described previously. ${ }^{16}$ For each sample solution, the ${ }^{1} \mathrm{H}$ NMR spectrum was measured at 25,35 , and $45^{\circ} \mathrm{C}$ at $400 \mathrm{MHz}$ on a JEOL $\lambda$-400 NMR spectrometer. The proton chemical shifts were recorded in ppm with tetramethylsilane (TMS) as an internal reference. Other details were described previously. ${ }^{16}$

\section{Results}

\section{Distribution experiments}

The pioneering work of Rais et al. ${ }^{1,21,22}$ showed that in the extraction of 1:1 salts into sufficiently polar solvents, such as $\mathrm{NB}$, the ionic association is not significant and the extraction equilibrium is given essentially by the distribution of ionic forms between the two phases. This is the case for the extraction of NaDPA, as also shown by our previous study, ${ }^{8}$ where the ionic association was completely ignored. By way of precaution, however, previous rigorous treatments ${ }^{1,21,23}$ considering a possible ion pair $\left(\mathrm{Na}^{+} \cdot \mathrm{DPA}^{-}\right)$in the $\mathrm{O}$ phase were performed. The distribution ratio of dipicrylaminate is expressed as

$$
\begin{aligned}
D_{\mathrm{DPA}} & =\frac{\left[\mathrm{DPA}^{-}\right]_{\mathrm{O}}+\left[\mathrm{Na}^{+} \cdot \mathrm{DPA}^{-}\right]_{\mathrm{O}}}{\left[\mathrm{DPA}^{-}\right]_{\mathrm{W}}} \\
& =\left(\frac{K_{\mathrm{ex}}\left[\mathrm{Na}^{+}\right]_{\mathrm{W}}}{\left[\mathrm{DPA}^{-}\right]_{\mathrm{W}}}\right)^{1 / 2}+K_{\mathrm{ex}}\left[\mathrm{Na}^{+}\right]_{\mathrm{W}} / K_{\mathrm{D}},
\end{aligned}
$$

where $K_{\text {ex }}$ and $K_{\mathrm{D}}$ are the extraction constant of NaDPA and the dissociation constant of the ion pair, respectively, which are defined by

$$
K_{\mathrm{ex}}=\frac{\left[\mathrm{Na}^{+}\right]_{\mathrm{o}}\left[\mathrm{DPA}^{-}\right]_{\mathrm{o}}}{\left[\mathrm{Na}^{+}\right]_{\mathrm{w}}\left[\mathrm{DPA}^{-}\right]_{\mathrm{W}}}
$$

and

$$
K_{\mathrm{D}}=\frac{\left[\mathrm{Na}^{+}\right]_{\mathrm{o}}\left[\mathrm{DPA}^{-}\right]_{\mathrm{o}}}{\left[\mathrm{Na}^{+} \cdot \mathrm{DPA}^{-}\right]_{\mathrm{O}}}
$$

In the above equations, the brackets, [ ]o and [ ]w, denote the equilibrium concentrations of a free ion or the ion pair in the $\mathrm{O}$ and $\mathrm{W}$ phases, respectively.

In this study, $D_{\mathrm{DPA}}$ was evaluated from the spectrophotometrically determined value of $\left[\mathrm{DPA}^{-}\right]_{\mathrm{w}}$ by considering the material balance,

$$
G_{\mathrm{DPA}}=\left[\mathrm{DPA}^{-}\right]_{\mathrm{W}} v_{\mathrm{W}}+D_{\mathrm{DPA}}\left[\mathrm{DPA}^{-}\right]_{\mathrm{w}} v_{\mathrm{O}},
$$

where $G_{\mathrm{DPA}}$ is the molar quantity of dipicrylaminate initially added to the $\mathrm{W}$ phase, and $v_{\mathrm{W}}$ and $v_{\mathrm{O}}$ are the volumes of the $\mathrm{W}$ and $\mathrm{O}$ phases, respectively (here, $v_{\mathrm{W}}=v_{\mathrm{O}}=25 \mathrm{~mL}$ ). The value of $\left[\mathrm{Na}^{+}\right]_{\mathrm{W}}$ in the right-hand-side of Eq. (1) can be obtained from $\left[\mathrm{DPA}^{-}\right]_{\mathrm{w}}$ by considering the addition of $0.1 \mathrm{M} \mathrm{NaCl}$ and the electroneutrality principle for the $\mathrm{W}$ phase,

$$
\left[\mathrm{Na}^{+}\right]_{\mathrm{W}}=0.1+\left[\mathrm{DPA}^{-}\right]_{\mathrm{W}}(\text { in } \mathrm{M}) \text {. }
$$

According to Eq. (1), therefore, $D_{\text {DPA }}$ divided by $\left[\mathrm{Na}^{+}\right]_{\mathrm{W}}$ should show a linear dependence on the quantity $\left(\left[\mathrm{Na}^{+}\right]_{\mathrm{W}}\left[\mathrm{DPA}^{-}\right]_{\mathrm{W}}\right)^{-1 / 2}$. In practice, we observed a linear $D_{\mathrm{DPA}}\left(\left[\mathrm{Na}^{+}\right]_{\mathrm{W}}\right)^{-1} v s$. $\left(\left[\mathrm{Na}^{+}\right]_{\mathrm{W}}\left[\mathrm{DPA}^{-}\right]_{\mathrm{W}}\right)^{-1 / 2}$ plot for each temperature, as shown in Fig. 1. This plot is essentially the same as that of Rais et al., ${ }^{21}$ though the ionic strength is different for the two studies.

From the slopes of the linear plots in Fig. $1, K_{\mathrm{ex}}$ was evaluated to be $6.9,4.7,4.5,2.9,2.3,2.3$, and 1.9 at $6,15,25,35,45,55$, and $65^{\circ} \mathrm{C}$, respectively. The intercepts of the linear plots (i.e., $\left.K_{\mathrm{ex}} / K_{\mathrm{D}}\right)$ gave ion-pair formation constants, $K_{\mathrm{A}}\left(=1 / K_{\mathrm{D}}\right)$, ranging from 47 to $91 \mathrm{M}^{-1}$. However, these values seem to be rather overestimated, since they are subject to a considerable error, as pointed out previously. ${ }^{21}$ Practically negligible ion-pair formation (i.e., $K_{\mathrm{A}}<5 \mathrm{M}^{-1}$ at $6-45^{\circ} \mathrm{C}$ ) of NaDPA in "watersaturated" NB has been confirmed by conductivity measurements using the reported method. ${ }^{10,24}$

Using the thus-determined $K_{\mathrm{ex}}$ values, the quantities of $-R T \ln$ $K_{\text {ex }}(R$, gas constant; $T$, absolute temperature) were plotted against $T$, and a good straight line with the correlation of 0.999 was obtained. Based on a general relation, $-R T \ln K_{\mathrm{ex}}=\Delta G^{*}=$ $\Delta H^{*}-T \Delta S^{*}$, the standard enthalpy and entropy for the extraction of NaDPA were evaluated as $\Delta H^{*}=-19.8 \pm 0.1 \mathrm{~kJ}$ $\mathrm{mol}^{-1}$ and $\Delta S^{*}=-48.1 \pm 0.2 \mathrm{~J} \mathrm{~K}^{-1} \mathrm{~mol}^{-1}$. These values are in fair agreement with the literature values: ${ }^{21} \Delta H^{*}=-18.7 \pm 1.3 \mathrm{~kJ}$ $\mathrm{mol}^{-1} ; \Delta S^{*}=-45.5 \pm 4.0 \mathrm{~J} \mathrm{~K}^{-1} \mathrm{~mol}^{-1}$ (these are average values for some data originally reported in units of cal).

The standard entropy of transfer of $\mathrm{Na}^{+}$from $\mathrm{NB}$ to $\mathrm{W}$ 


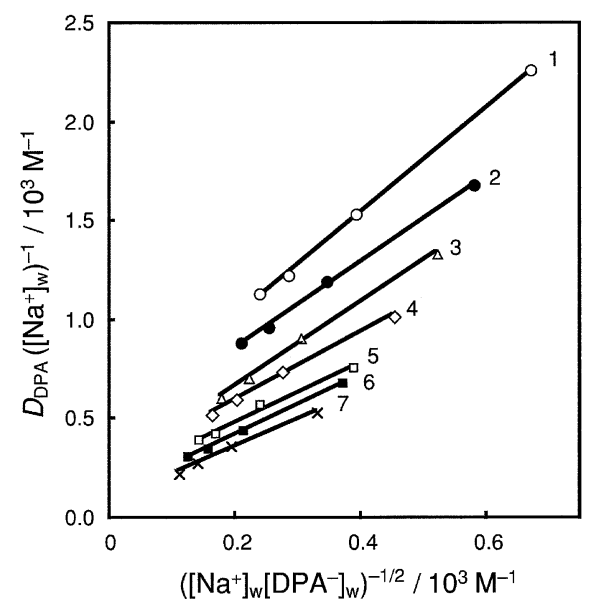

Fig. 1 Extraction of NaDPA into NB at different temperatures: (1) 6 , (2) 15 , (3) 25 , (4) 35 , (5) 45 , (6) 55 , and (7) $65^{\circ} \mathrm{C}$.

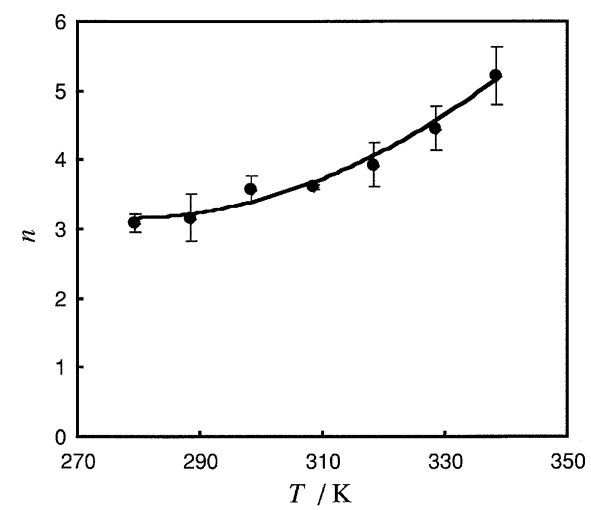

Fig. 2 Temperature dependence of the $n$ value of $\mathrm{Na}^{+}$.

$\left(\Delta S_{\mathrm{tr}, \mathrm{Nat}}^{\mathrm{o}, \mathrm{O} \rightarrow \mathrm{W}}=+28.8 \mathrm{~J} \mathrm{~K}^{-1} \mathrm{~mol}^{-1}\right)$ has recently been reported along with the corresponding enthalpy $\left(\Delta H_{\mathrm{tr}, \mathrm{O} a+}^{\mathrm{O}, \mathrm{W}}=-25.6 \mathrm{~kJ} \mathrm{~mol}^{-1}\right) .{ }^{20}$ Because $\Delta S^{*}$ is composed of two contributions from $\mathrm{Na}^{+}$and $\mathrm{DPA}^{-}$, i.e., $-\Delta S^{*}=\Delta S_{\mathrm{tr}, \mathrm{Na}+}^{\mathrm{oO} \rightarrow \mathrm{W}}+\Delta S_{\mathrm{tr}, \mathrm{DPA}-}^{\mathrm{o}, \mathrm{O}} \rightarrow$, the value of $\Delta S_{\mathrm{tr}, \mathrm{DPA}}^{\mathrm{o}, \mathrm{OP}}-$ is obtained to be $+19.3 \mathrm{~J} \mathrm{~K}^{-1} \mathrm{~mol}^{-1}$. The enthalpy value, $\Delta H_{\mathrm{tr}, \mathrm{DPA}}^{\mathrm{o}, \mathrm{W}}$, is likewise evaluated to be $+45.4 \mathrm{~kJ} \mathrm{~mol}^{-1}$.

The water concentration in NB, determined by the Karl Fischer method, increased linearly with the equilibrium concentration of $\mathrm{Na}^{+}$in $\mathrm{NB}$ at all temperatures, as previously observed at $25^{\circ} \mathrm{C}{ }^{8}$ From the slope of a linear plot at each temperature, the $n$ value of $\mathrm{Na}^{+}$was determined, based on knowledge that the hydrophobic DPA $^{-}$ion has no ability to transport water to NB. ${ }^{8}$ As shown in Fig. 2 , the $n$ value increased from $3.1\left(6^{\circ} \mathrm{C}\right)$ to $5.2\left(65^{\circ} \mathrm{C}\right)$.

\section{${ }^{1} \mathrm{H}$ NMR measurements}

Figure 3 shows a typical NMR spectrum, which was obtained for a $2.5 \mathrm{mM} \mathrm{NaDPA} \mathrm{NB}-\mathrm{d}_{5}$ solution containing $121 \mathrm{mM} \mathrm{H}_{2} \mathrm{O}$ at $25^{\circ} \mathrm{C}$. As can be seen in the figure, the water protons always appeared as a singlet, showing that the exchange of water molecules between the free and $\mathrm{Na}^{+}$-bound forms is very fast. Under these conditions, the chemical shift of water protons should change with the distribution of water molecules between the free and ion-bound forms. The assignments of other signals are as follows. The signal at $8.8 \mathrm{ppm}$ is due to the protons of $\mathrm{DPA}^{-}$and those around 7.5, 7.7, and $8.1 \mathrm{ppm}$ are assigned, respectively, to $m-, p$-, and $o$-protons of the benzene ring of NB

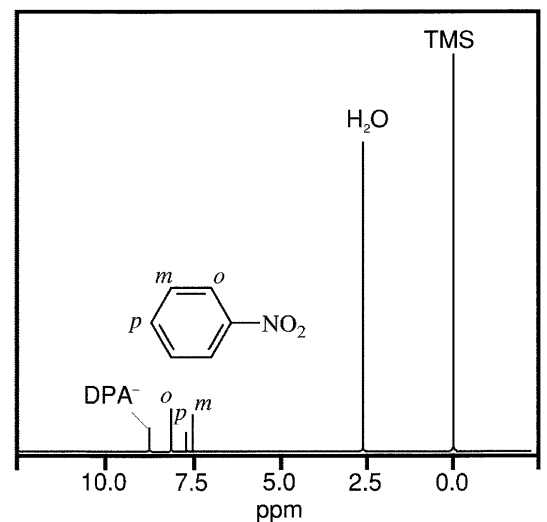

Fig. $3 \quad{ }^{1} \mathrm{H}$ NMR spectrum of $2.5 \mathrm{mM}$ NaDPA in NB- $\mathrm{d}_{5}$ containing $121 \mathrm{mM} \mathrm{H}_{2} \mathrm{O}$ at $25^{\circ} \mathrm{C}$.

that remained undeuterated.

In Fig. 4, the chemical shift of water protons, $\delta$ [ppm], is plotted against the total (i.e., added) water concentration, $\left[\mathrm{H}_{2} \mathrm{O}\right]_{\text {total }}$, for three different concentrations of NaDPA (i.e., $\mathrm{Na}^{+}$) at $25^{\circ} \mathrm{C}$. Similar plots were also obtained at 35 and $45^{\circ} \mathrm{C}$. As can be seen in Fig. 4, the chemical shift of the water protons increased with increasing ion concentration. Such a dependence is analogous to that observed for inorganic anions ${ }^{16}\left(\mathrm{Cl}^{-}, \mathrm{Br}^{-}, \mathrm{I}^{-}\right.$, etc.), and could likewise be simulated by assuming successive hydration:

$$
\begin{aligned}
& \mathrm{Na}^{+}+\mathrm{H}_{2} \mathrm{O} \rightleftharpoons \mathrm{Na}^{+}\left(\mathrm{H}_{2} \mathrm{O}\right), \\
& \mathrm{Na}^{+}\left(\mathrm{H}_{2} \mathrm{O}\right)+\mathrm{H}_{2} \mathrm{O} \rightleftharpoons \mathrm{Na}^{+}\left(\mathrm{H}_{2} \mathrm{O}\right)_{2}, \\
& \mathrm{Na}^{+}\left(\mathrm{H}_{2} \mathrm{O}\right)_{2}+\mathrm{H}_{2} \mathrm{O} \rightleftharpoons \mathrm{Na}^{+}\left(\mathrm{H}_{2} \mathrm{O}\right)_{3},
\end{aligned}
$$

In this mechanism the observed chemical shift of water protons is given by

$$
\begin{aligned}
\delta= & \delta_{\text {blank }}+\frac{\left[\mathrm{Na}^{+}\left(\mathrm{H}_{2} \mathrm{O}\right)\right]}{\left[\mathrm{H}_{2} \mathrm{O}\right]_{\text {total }}} \delta_{1}+2 \frac{\left[\mathrm{Na}^{+}\left(\mathrm{H}_{2} \mathrm{O}\right)_{2}\right]}{\left[\mathrm{H}_{2} \mathrm{O}\right]_{\text {total }}} \delta_{1}+ \\
& 3 \frac{\left[\mathrm{Na}^{+}\left(\mathrm{H}_{2} \mathrm{O}\right)_{3}\right]}{\left[\mathrm{H}_{2} \mathrm{O}\right]_{\text {total }}} \delta_{3}+\cdots+m \frac{\left[\mathrm{Na}^{+}\left(\mathrm{H}_{2} \mathrm{O}\right)_{m}\right]}{\left[\mathrm{H}_{2} \mathrm{O}\right]_{\text {total }}} \delta_{m}+\cdots \\
= & \delta_{\text {blank }}+\frac{K_{1}\left[\mathrm{Na}^{+}\right]\left[\mathrm{H}_{2} \mathrm{O}\right]}{\left[\mathrm{H}_{2} \mathrm{O}\right]_{\text {total }}} \delta_{1}+2 \frac{K_{1} K_{2}\left[\mathrm{Na}^{+}\right]\left[\mathrm{H}_{2} \mathrm{O}\right]^{2}}{\left[\mathrm{H}_{2} \mathrm{O}\right]_{\text {total }}} \delta_{2}+ \\
& \frac{3 K_{1} K_{2} K_{3}\left[\mathrm{Na}^{+}\right]\left[\mathrm{H}_{2} \mathrm{O}\right]^{3}}{\left[\mathrm{H}_{2} \mathrm{O}\right]_{\text {total }}} \delta_{3}+\cdots \\
& +m \frac{K_{1} K_{2} K_{3} \cdots K_{m}\left[\mathrm{Na}^{+}\right]\left[\mathrm{H}_{2} \mathrm{O}\right]^{m}}{\left[\mathrm{H}_{2} \mathrm{O}\right]_{\text {total }}} \delta_{m}+\cdots,
\end{aligned}
$$

where $\delta_{m}(m=1,2,3, \cdots)$ is the intrinsic chemical shift for an $m$ hydrated ion, $\mathrm{Na}^{+}\left(\mathrm{H}_{2} \mathrm{O}\right)_{m}$, and $K_{m}$ is the successive formation constant of the $m$-hydrated ion, defined by

$$
K_{m}=\frac{\left.\left[\mathrm{Na}^{+}\right]\left(\mathrm{H}_{2} \mathrm{O}\right)_{m}\right]}{\left[\mathrm{Na}^{+}\left(\mathrm{H}_{2} \mathrm{O}\right)_{m-1}\right]\left[\mathrm{H}_{2} \mathrm{O}\right]}(m=1,2,3, \cdots) .
$$

In Eq. (7), the term $\delta_{\text {blank }}$ represents the chemical shift for a "blank" solvent, i.e., NB-d $\mathrm{d}_{5}$ containing no ions. Since it was reported that water exists as a monomer or dimer in $\mathrm{NB},{ }^{25}$ we assumed a monomer-dimer equilibrium:

$$
2 \mathrm{H}_{2} \mathrm{O} \rightleftharpoons\left(\mathrm{H}_{2} \mathrm{O}\right)_{2} \text {. }
$$




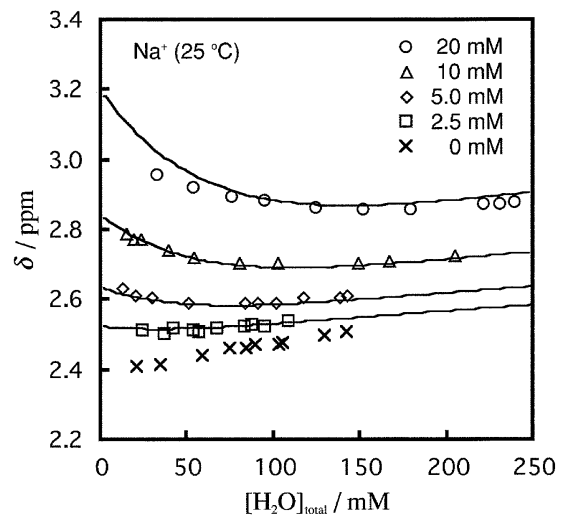

Fig. 4 Plots of the chemical shift of water protons against the water concentration for $20,10,5.0,2.5$, and $0 \mathrm{mM} \mathrm{Na}^{+}$in NB-d $\mathrm{d}_{5}$ at $25^{\circ} \mathrm{C}$. The solid lines show the best fits to the experimental data with a successive hydration mechanism.

Accordingly, $\delta_{\text {blank }}$ is given by

$$
\begin{aligned}
\delta_{\text {blank }} & =\frac{\left[\mathrm{H}_{2} \mathrm{O}\right]}{\left[\mathrm{H}_{2} \mathrm{O}\right]_{\text {total }}} \delta_{\text {mono }}+2 \frac{\left[\left(\mathrm{H}_{2} \mathrm{O}\right)_{2}\right]}{\left[\mathrm{H}_{2} \mathrm{O}\right]_{\text {total }}} \delta_{\text {di }} \\
& =\frac{\left[\mathrm{H}_{2} \mathrm{O}\right]}{\left[\mathrm{H}_{2} \mathrm{O}\right]_{\text {total }}} \delta_{\text {mono }}+2 \frac{K_{\mathrm{s}}\left[\mathrm{H}_{2} \mathrm{O}\right]^{2}}{\left[\mathrm{H}_{2} \mathrm{O}\right]_{\text {total }}} \delta_{\text {di }},
\end{aligned}
$$

where $\delta_{\text {mono }}$ and $\delta_{\mathrm{di}}$ are the intrinsic chemical shifts of the monomer and dimer, respectively, and $K_{\mathrm{s}}$ is the monomer-dimer equilibrium constant for water in NB,

$$
K_{\mathrm{s}}=\frac{\left[\left(\mathrm{H}_{2} \mathrm{O}\right)_{2}\right]}{\left[\mathrm{H}_{2} \mathrm{O}\right]^{2}}
$$

The $K_{\mathrm{s}}$ value was reported to be $1.054 \mathrm{M}^{-1}$ at $25^{\circ} \mathrm{C} .25,26$ Using Eq. (10) with this value, the experimental data shown by the crosses in Fig. 4 were simulated well with $\delta_{\text {mono }}(=2.40 \mathrm{ppm})$ and $\delta_{\mathrm{di}}(=2.87 \mathrm{ppm})$ as fitting parameters. ${ }^{16}$ Unfortunately, however, there are no data available on the $K_{\mathrm{s}}$ values for other temperatures. Therefore, the value of $1.054 \mathrm{M}^{-1}$ was also employed for the $K_{\mathrm{s}}$ values at 35 and $45^{\circ} \mathrm{C}$. Although the true values would be somewhat different, a deviation on the order of 20-30\% hardly influenced the results of the theoretical analyses described below.

The terms in Eqs. (7) and (10) are interdependent of each other, because each term involves the concentration of monomeric water, $\left[\mathrm{H}_{2} \mathrm{O}\right]$. However, the crucial parameters $\left(\delta_{m}\right.$, $K_{m}, K_{s}$, etc.) involved in those terms are likely to be independent of each other, in the studied concentration range. Using the $K_{m}$ values, the concentration of the nonhydrated ion, $\left[\mathrm{Na}^{+}\right]$, is given by

$$
\begin{aligned}
{\left[\mathrm{Na}^{+}\right]=} & {\left[\mathrm{Na}^{+}\right]_{\text {total }} /\left\{1+K_{1}\left[\mathrm{H}_{2} \mathrm{O}\right]+K_{1} K_{2}\left[\mathrm{H}_{2} \mathrm{O}\right]^{2}+\right.} \\
& \left.K_{1} K_{2} K_{3}\left[\mathrm{H}_{2} \mathrm{O}\right]^{3}+\cdots+\left(K_{1} K_{2} K_{3} \cdots K_{m}\right)\left[\mathrm{H}_{2} \mathrm{O}\right]^{m}+\cdots\right\},
\end{aligned}
$$

where $\left[\mathrm{Na}^{+}\right]_{\text {total }}$ is the total concentration of $\mathrm{Na}^{+}$.

Based on the above equations, the experimental data, as shown in Fig. 4, were fitted to theoretical curves by assuming $m$ $=1-6$. The detailed method of calculation was previously described. ${ }^{16}$ As shown in Fig. 4, a satisfactory agreement was obtained between the experimental and theoretical curves at all temperatures, giving the values of $K_{m}, \delta_{m}$, etc. as listed in Table 1.

It should be noted that the values of $K_{m}$ and $\delta_{m}$ were obtained
Table 1 Values of $K_{m}\left(\mathrm{M}^{-1}\right)$ and $\delta_{m}(\mathrm{ppm})$ obtained from curve fittings at three different temperatures

\begin{tabular}{lccl}
\hline & \multicolumn{3}{c}{$T / \mathrm{C}^{\circ}$} \\
\cline { 2 - 4 } & 25 & 35 & 45 \\
\hline$K_{1}$ & 11 & 8.8 & 8.7 \\
$K_{2}$ & 7.5 & 5.0 & 5.0 \\
$K_{3}$ & 3.3 & 3.2 & 3.1 \\
$K_{4}$ & 3 & 2 & 2 \\
$K_{5}$ & 2 & 2 & 1 \\
$K_{6}$ & 2 & 1 & 0.5 \\
$\delta_{1}$ & 6.8 & 7.1 & 7.1 \\
$\delta_{2}$ & 2.7 & 2.5 & 2.0 \\
$\delta_{3}$ & 5 & 5.5 & 6.0 \\
$\delta_{4}$ & 7 & 6 & 7 \\
$\delta_{5}$ & 8 & 8 & 8 \\
$\delta_{6}$ & 9 & 9 & 9 \\
$\delta_{\text {mono }}$ & 2.40 & 2.35 & 2.28 \\
$\delta_{\text {di }}$ & 2.87 & 2.83 & 2.78 \\
$\sigma^{\text {a }}$ & 0.012 & 0.019 & 0.089 \\
$n^{\text {b }}$ & 3.60 & 3.63 & 3.95 \\
$\langle n\rangle^{\text {c }}$ & 4.1 & 4.3 & 4.7 \\
{$\left[\mathrm{H}_{2} \mathrm{O}\right]_{\text {blank }}$} & 168 & 211 & 270 \\
\hline
\end{tabular}

a. Standard deviation, $\sigma=\left[\sum\left(\delta_{\text {calcd }}-\delta_{\text {obsd }}\right)^{2} /(N-1)\right]^{1 / 2}$, where $\delta_{\text {calcd }}$ and $\delta_{\text {obsd }}$ stand for the calculated and observed chemical shifts, respectively, and $N$ is the number of data points.

b. Hydration number of $\mathrm{Na}^{+}$in NB shown in Fig. 2 .

c. Average hydration number calculated from the $K_{m}$ values.

d. Concentration of water saturated in the blank solvent.

as adjusting parameters, and that as many as twelve parameters were used for each temperature. Accordingly, these parameters could not be uniquely determined; a set of parameters obtained for each temperature should be regarded as one of the best parameter sets that could give us a satisfactory result of the curve fitting. Although this prevents us from examining those parameters closely, we would like to claim that there is a notable tendency of $K_{m}$ to decrease with the temperature. This agrees with our expectation that hydration would generally be an entropically unfavorable process. Regarding the $\delta_{m}$ values, no marked dependence on the temperature was observed.

The curve-fitting analyses mentioned above have clearly shown that the selective hydration of $\mathrm{Na}^{+}$in $\mathrm{NB}$ can be elucidated in terms of the successive reaction mechanism. A one-step reaction mechanism ${ }^{16}$ (e.g. $\mathrm{Na}^{+}+4 \mathrm{H}_{2} \mathrm{O} \rightleftharpoons$ $\left.\mathrm{Na}^{+}\left(\mathrm{H}_{2} \mathrm{O}\right)_{4}\right)$ could not be used to elucidate the dependence of $\delta$ shown in Fig. 4.

The average hydration number of $\mathrm{Na}^{+}$was calculated using

$$
\langle n\rangle=\frac{\sum_{m} m\left(\left[\mathrm{Na}^{+}\left(\mathrm{H}_{2} \mathrm{O}\right)_{m}\right]_{\text {sat }}\right)}{\left[\mathrm{Na}^{+}\right]_{\text {total }}},
$$

where $\left[\mathrm{Na}^{+}\left(\mathrm{H}_{2} \mathrm{O}\right)_{m}\right]_{\text {sat }}$ represents the concentration of the $m$ hydrated ion in the water-saturated solvent. As can be seen in Table 1 , the $\langle n\rangle$ values are in reasonable agreement with the $n$ values determined by the Karl Fischer method, though the former are somewhat larger than the latter.

\section{Discussion}

The results of the present distribution experiments are basically in line with those reported by Rais et al..$^{21}$ The negative value of $\Delta S^{*}\left(=-48.1 \mathrm{~J} \mathrm{~K}^{-1} \mathrm{~mol}^{-1}\right)$ means that the extraction of NaDPA 


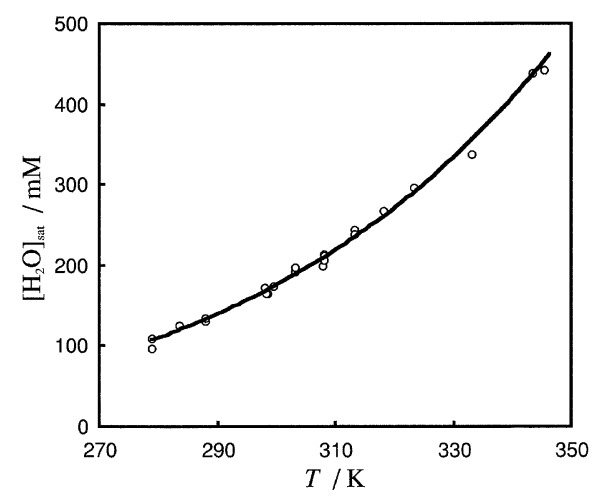

Fig. 5 Temperature dependence of the concentration of water saturated in pure NB.

into NB is entropically unfavorable, or suppressed with increasing temperature. As shown above, the negative $\Delta S^{*}$ value comes from the contributions of both $\mathrm{Na}^{+}$and $\mathrm{DPA}^{-}$; note

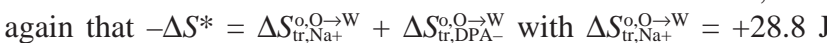
$\mathrm{K}^{-1} \mathrm{~mol}^{-1}$ and $\Delta S_{\mathrm{tr}, \mathrm{OPA}}^{\mathrm{o}, \mathrm{W}}=+19.3 \mathrm{~J} \mathrm{~K}^{-1} \mathrm{~mol}^{-1}$. Although $\mathrm{Na}^{+}$is known to be a water-structure making ion,,$^{27,28}$ the value of $\Delta S_{\mathrm{tr}, \mathrm{Na+}}^{\mathrm{o}, \mathrm{W}}$ may suggest some sort of a breaking effect on the water structure. As discussed in a recent paper, ${ }^{20}$ this is probably because the highly organized structure of water molecules in the first solvation shell around $\mathrm{Na}^{+}$would be maintained even in water-saturated NB. The water-structure making in the first solvation shell should contribute to the hydration entropy, but appears not to contribute to the transfer entropy. With regard to $\mathrm{DPA}^{-}$, the positive entropy change for its transfer from NB to W is curious because a strongly hydrophobic ion, such as tetrabutylammonium ion, generally acts as a structure promoter in water. ${ }^{27,28}$ It appears likely that a structural similarity of $\mathrm{DPA}^{-}$and $\mathrm{NB}$ results in a structure promotion or structurestabilizing effect of $\mathrm{DPA}^{-}$in NB.

The Karl Fischer measurements have shown that the hydration number of $\mathrm{Na}^{+}$in NB increases with the temperature, as shown in Fig. 2. This result is seemingly curious, because hydration or solvation would generally be an entropically unfavorable process. In fact, an analysis of the NMR chemical shifts has shown that the successive hydration constants $\left(K_{m}\right)$ of $\mathrm{Na}^{+}$in NB tend to decrease with the temperature (Table 1). However, the concentration of water saturated in pure NB has a much stronger temperature dependence due to the mixing entropy, as shown in Fig. 5. We then employed the $K_{m}$ values to calculate the distribution of $\mathrm{Na}^{+}$ions in several hydration states, as a function of $\left[\mathrm{H}_{2} \mathrm{O}\right]_{\text {total }}$ for three different temperatures (Fig. 6). Reflecting the temperature dependence of $K_{m}$, the fractions of more highly hydrated ions at a definite water concentration decrease with increasing temperature. Nevertheless, at the water concentrations where $\mathrm{NB}$ containing $5.0 \mathrm{mM} \mathrm{Na}^{+}$is saturated with water (i.e., $\left[\mathrm{H}_{2} \mathrm{O}\right]_{\text {total }}=186,229$, and $290 \mathrm{mM}$ at 25,35 , and $45^{\circ} \mathrm{C}$, respectively), more highly hydrated ions appear to become more dominant with increasing temperature. Thus, the effect of the mixing entropy is so strong that it overcomes the decrease in $K_{m}$ with temperature, resulting in an increase in the apparent hydration number with increasing temperature (Fig. 2).

\section{References}

1. J. Rais, M. Kyrš, and M. Pivon̆ková, J. Inorg. Nucl. Chem.,

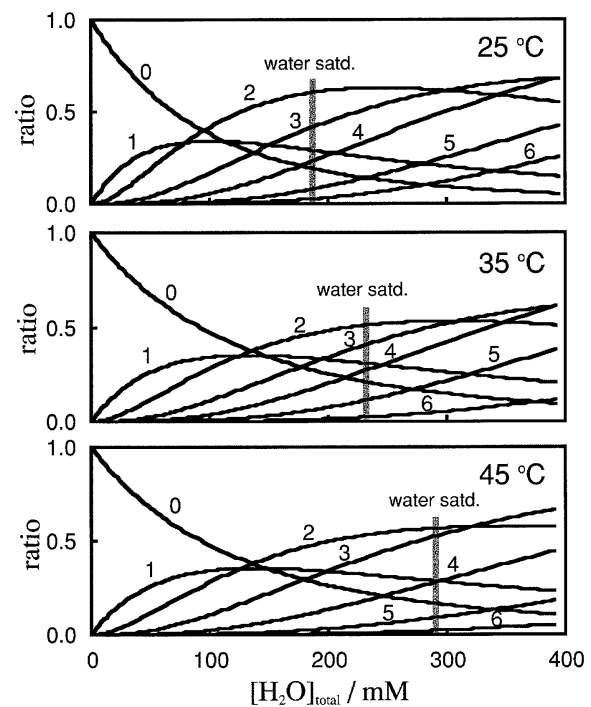

Fig. 6 Distribution of $\mathrm{Na}^{+}$ions in several hydration states as a function of the water concentration at three different temperatures: (0) nonhydrated; (1) monohydrated; (2) dihydrated; (3) trihydrated; (4) tetrahydrated; (5) pentahydrated; and (6) hexahydrated. $\left[\mathrm{Na}^{+}\right]_{\text {total }}$ $=5 \mathrm{mM}$.

1968, 30, 611.

2. S. Motomizu, K. Tôei, and T. Iwachido, Bull. Chem. Soc. Jpn., 1969, 42, 1006.

3. T. Kenjo and R. M. Diamond, J. Phys. Chem., 1972, 76, 2454.

4. T. Kenjo and R. M. Diamond, J. Inorg. Nucl. Chem., 1974, 36, 183.

5. Y. Yamamoto, T. Tarumoto, and T. Tarui, Bull. Chem. Soc. Jpn., 1973, 46, 1466.

6. S. Kusakabe, M. Shinoda, and K. Kusafuka, Bull. Chem. Soc. Jpn., 1989, 62, 333.

7. S. Kusakabe and M. Arai, Bull. Chem. Soc. Jpn., 1996, 69, 581.

8. T. Osakai, A. Ogata, and K. Ebina, J. Phys. Chem. B, 1997, $101,8341$.

9. T. Osakai, "Interfacial Catalysis", ed. A. G. Volkov, 2002, Marcel Dekker, New York, 53.

10. A. Ogata, Y. Tsujino, and T. Osakai, Phys. Chem. Chem. Phys., 2000, 2, 247.

11. T. Osakai, S. Nakata, and H. Ogawa, Chem. Lett., 2001, 558.

12. Y. Marcus, "Ion Solvation", 1985, Wiley, Chichester, 184.

13. I. Benjamin, Science, 1993, 261, 1558.

14. I. Benjamin, "Liquid-Liquid Interfaces, Theory and Methods", ed. A. G. Volkov and D. W. Deamer, 1996 CRC Press, Boca Raton, 179.

15. M. Lauterbach, G. Wipff, A. Mark, and W. F. van Gunsteren, Gazz. Chim. Ital., 1997, 127, 699.

16. T. Osakai, M. Hoshino, M. Izumi, M. Kawakami, and K. Akasaka, J. Phys. Chem. B, 2000, 104, 12021.

17. T. Osakai and K. Ebina, J. Phys. Chem. B, 1998, 102, 5691.

18. T. Osakai and K. Ebina, "Liquid Interfaces in Chemical, Biological, and Pharmaceutical Applications", ed. A. G. Volkov, 2001, Marcel Dekker, New York, 23.

19. C. Sánchez, E. Leiva, S. A. Dassie, and A. M. Barussi, Bull. Chem. Soc. Jpn., 1998, 71, 549.

20. T. Osakai, H. Ogawa, T. Ozeki, and H. H. Girault, J. Phys. Chem. B, 2003, 107, 9829. 
21. J. Rais, M. Pacltová-Benešová, P. Selucký, and M. Kyrš, J. Inorg. Nucl. Chem., 1973, 35, 633.

22. J. Rais, Coll. Czech. Chem. Commun., 1971, 36, 3253.

23. M. Kyrš, Coll. Czech. Chem. Commun., 1962, 27, 155.

24. M. Gérin and J. Fresco, Anal. Chim. Acta, 1978, 97, 165.

25. J. R. Johnson, S. D. Christian, and H. E. Affsprung, J.
Chem. Soc. A, 1967, 1924.

26. K. Ito, E. Iwamoto, and Y. Yamamoto, Bull. Chem. Soc. Jpn., 1983, 56, 2290.

27. H. S. Frank and W.-Y. Wen, Disc. Faraday Soc., 1957, 24, 133.

28. O. Ya. Samoilov, Disc. Faraday Soc., 1957, 24, 141. 